\title{
Effects of muscle length on an increased stretch reflex in children with cerebral palsy
}

\author{
G TARDIEU, C TARDIEU, P COLBEAU-JUSTIN, MD BRET \\ From the Hôpital Raymond Poincaré, Garches, France
}

SUMMARY No inhibitory influence of length on the increased stretch reflex was found in the internal gastrocnemius muscle of 19 cerebral palsied children. A facilitory influence of length was found in at least five patients in which quantitative data were obtained. These results were compared with previous data on a facilitory influence in the hamstrings and inhibitory influence in quadriceps muscles.

Since Charcot's finding ${ }^{1}$ that spastic muscle resistance suddenly may disappear, and especially since Sherrington ${ }^{2}$ described the clasp knife phenomenon in spinal dogs, many clinicians have observed this phenomenon in spastic patients. It must be stressed that Sherrington ${ }^{2}$ found the clasp knife phenomenon, that is the abolition of resistance during the stretching movement, only in spinal dogs. The decerebrate cat exhibited only the lengthening reaction, the knee remained in the new posture; that is on cessation of flexion. A further flexion met with further resistance. Liddel and Sherrington ${ }^{3}$ were unable to demonstrate a length inhibitory response in the quadriceps of the decerebrate cat. The question has aroused current interest since it was demonstrated recently that the clasp knife reflex, which was absent in the cat after decerebration, appeared when dorsal hemisection of the lower thoracic cord subsequently was performed. 4

Numerous authors have considered that, in human spasticity, hypertonicity melts away as stretch increases, or have even considered this feature to be essential for the diagnosis of spasticity. However, a pseudo clasp knife phenomenon may occur for many reasons. ${ }^{5-7}$ It has been demonstrated in spastic patients (most of them with spinal lesions, but several with cerebral lesions) that the effect of increasing muscle length is inhibitory in the quadriceps, but facilitory in the hamstrings and in the biceps and triceps muscles of the upper limb..$^{8-11}$ We have investigated whether the inhibitory effect

Address for reprint requests: Pr G Tardieu, U215 INSERM Hôpital Raymond Poincaré, 92380 Garches, France.

Received 28 July 1981 and in revised form 17 October 1981 Accepted 18 November 1981 of length occurs in all the spastic extensor muscles of the lower limbs, or only in the quadriceps muscle. Such an effect in the triceps surae muscle seemed improbable, for it is not evident clinically. However, the problem is complicated because a passive elastic resistance of the non-contracting triceps surae muscle is present in normal subjects, and is often greatly increased in so called spastic patients. For this reason, it remained possible that an inhibitory effect of length on the reflex itself could be demonstrated in triceps surae by an electromyographic method, as has been used for other muscles. ${ }^{8} 1011$

\section{Patients}

19 children (aged 4-12 years) were studied; all had congenital cerebral lesions with greatly increased stretch reflexes of the triceps surae. For this reason, they were considered as suffering from a spastic form of cerebral palsy: 11 were diplegic, five were quadriplegic, three were hemiplegic.

\section{Method}

A device was constructed to record the EMG and the tibiocalcaneal angle (fig 1). The apparatus as well as the electronic and additional measurements have been described in detail elsewhere. ${ }^{1213}$ The child was placed lying on his side, the leg was fixed onto a frame with the knee fully extended, the sole of the foot resting on a mobile plate. The effect of muscle length on the stretch reflex was tested by two types of manually stretching movements, both performed on a horizontal plane: (1) sequential linear stretchings with steps of equal amplitude (20 degrees), (2) stretching cycles of 20 degrees amplitude at different centres of oscillation. For instance, the centre of oscillation was $120^{\circ}$ when the cycle was 


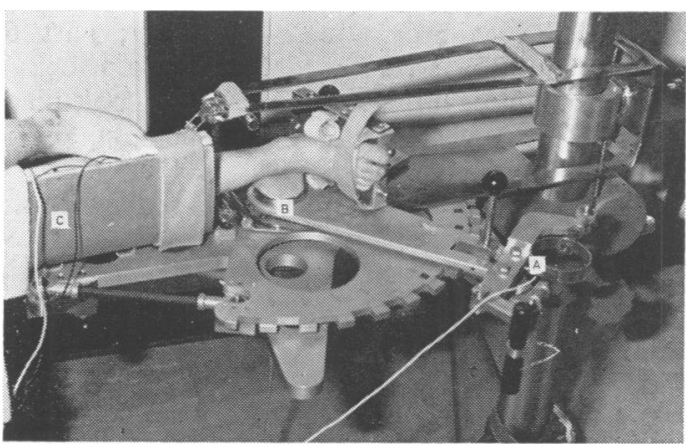

Fig 1 Part of the device for measurement of triceps surae torques $(A)$, tibio-calcaneal angle $(B), E M G$ and integrated EMG of internal gastrocnemius, soleus and tibialis anterior (leads in $C$ ). Electronic recording equipment not shown.

performed between 130 and 110 . In addition, the oscillatory movements were used to examine the relationship of reflex EMG to the phase of an oscillatory cycle.

The following points are stressed regarding records of angles, torques and EMG. For the tibiocalcaneal angles, the presence in some children of a myostatic contracture (that is excessive resistance of the muscle when not contracting) prevented us from obtaining more than 2-3 steps of linear stretching or centres of oscillations. On the other hand, the presence of transient timedependent viscoelastic phenomena in the mediotarsalis joint prevented the foot-plate records from being reliably related to the tibiocalcaneal angle when the speed of the stretching cycles was fast. For this reason, stretching cycles were used at a speed no faster than 1 per second. The torque was recorded by the apparatus. However, it was not further taken into account because there was interference with the true stretch reflex torque, the elastic, and especially the time-dependent viscoelastic torques, which developed even in the non-contracting muscle. This non-reflex component of tension was evident in another study, and prompted measurement of tension in quadriceps and hamstrings. ${ }^{10} 11$

The EMG was recorded from the medial head of the gastrocnemius, the soleus and tibialis anterior muscles. However, in the present study, only the gastrocnemius direct and integrated EMG were taken into account, as the soleus activity was found to be similar to that of gastrocnemius. Beckman surface electrodes $(1 \mathrm{~cm}$ diameter) were used, with an inter-electrode distance of $2.5 \mathrm{~cm}$ for each muscle. The potentials were rectified and integrated (time constant $0.02 \mathrm{~s}$ ). The three direct EMGs, the true integrated EMG, the resistive torque and the tibiocalcaneal angles were recorded using a 6channel San-Ei Visigraph. The EMG was monitored on a oscilloscope to detect artifacts before or during stretching movements.

For various reasons, we could not obtain sufficient data in a number of cases. Firstly, the stretch reflex fatigue observed in adults ${ }^{810}$ is much more frequent in cerebral palsied children. After a few oscillations, and especially after a few ramp movements, the EMG of the stretch reflex decreased considerably in many children. For instance, one child's record was discarded because of the disappearance of any stretch reflex activity after three cycles, while in another child no fatigue was observed after 35 cycles. Secondly, as noted above, we had to employ cycles no faster than $1 \mathrm{~Hz}$. The low threshold of the stretch reflex prevented us from obtaining the stretch reflex at this frequency in many patients. Thirdly, in some children the stretching, and particularly the oscillatory stretches, caused artefacts which prevented a reliable investigation of a relationship between reflex EMG and the phase of an oscillatory cycle. For these reasons the studies of many children were discarded, leaving only 19 children to be considered. Only a qualitative appreciation was possible in 14 cases. However, quantitative measurements were possible in five others: During oscillations Two methods were used to demonstrate the influence of the muscle imposed length on the integrated EMG. In both methods the cycles were discarded when they were disturbed by the child's movements. (a) for two children, the oscillations were studied at low frequency $(0 \cdot 25 \mathrm{~Hz})$. Each cycle was divided into six portions (diagram, fig 2 inset); the EMG was measured for each part. The results were expressed as percentages of the data of the third part corresponding to the maximum length of the muscle. In this way, the influence of lengthening was evaluated whatever the centre of oscillation, (b) for five children, the EMG was integrated over each $500 \mathrm{~ms}$. Obviously, for each cycle the number of such integrals depended on the frequency ( 8 for $0.25 \mathrm{~Hz}$, 4 for $0.50 \mathrm{~Hz}, 2$ for $1 \mathrm{~Hz}$ ). Amongst these values, some were high corresponding to the part of the cycle in which there was a maximum myotatic activity. The means of these highest values were calculated and were compared according to the centres of oscillations.

This method cannot provide a valid assessment of the influence of velocity. Since the $500 \mathrm{~ms}$ period of integration covers half a cycle at $1 \mathrm{~Hz}$, activity is measured over a much larger range of muscle lengths than when the frequency is at $0.25 \mathrm{~Hz}$; any comparison made between frequencies should be subject to criticism.

During ramp movements, the integrated EMG was measured over $100 \mathrm{~ms}$ with stretches of progressive steps of equal amplitude $\left(20^{\circ}\right)$ but fixed velocity.

\section{Results}

In the 14 children in which only a qualitative appreciation was possible, there was no evidence of an inhibitory effect of increasing length on the exaggerated stretch reflex either in oscillatory cycles or in ramp movements. In the other five children, the quantitative measurements gave evidence of a facilitatory effect of muscle length on the stretch reflex of the triceps surae.

(A) RELATIONSHIP OF REFLEX EMG TO THE PHASE OF OSCILLATORY CYCLES

For case LP, the centres of oscillations were $125^{\circ}$, 


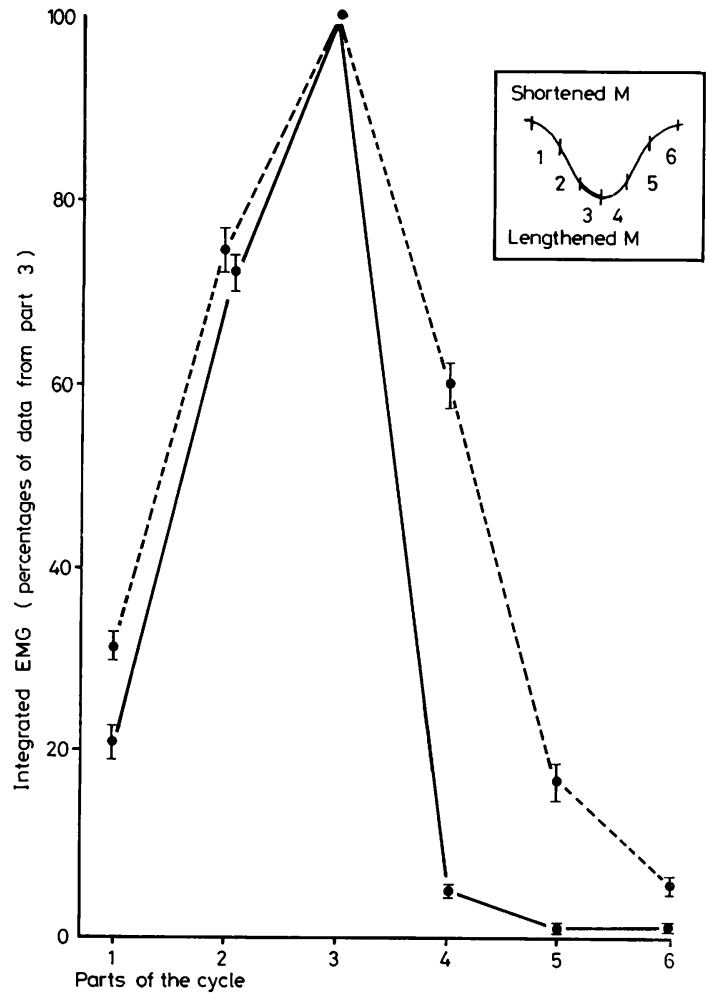

Fig 2 Mean $( \pm S E M)$ of internal gastrocnemius integrated EMG, expressed as a percentage, of part 3 of the cycle (maximum length and decreasing positive velocity) during $0.25 \mathrm{~Hz}$ oscillations. — child $F L$; --- child $L P$.

$120^{\circ}, 115^{\circ}, 110^{\circ}$ and $105^{\circ}$; for case $\mathrm{FL}$, centres of oscillations were $130^{\circ}, 120^{\circ}$, and $110^{\circ}$. Nine cycles were measured in each situation. Table 1 and figure 2 show the means $( \pm 1$ SEM) for the six parts of the cycle expressed in percentage of data measured during part 3 (part 1: minimum length and increasing positive velocity; part 2 : mean length and maximum positive velocity; part 3 : maximum length and decreasing positive velocity; part 4: maximum length and negative increasing velocity; part 5: mean length and maximum negative velocity; part 6 : minimum length and decreasing negative velocity). In both children, the maximum activity took place in part 3 (which is related to maximum length of the the muscle with decreasing positive velocity).

In table 2 and fig 3, the results are not expressed in percentage, but in arbitrary units of integrated EMG activity. For each centre of oscillation, there was a peak for part 3. So maximum EMG activity was in phase with maximum length and not with maximum velocity. For the whole of the curves, the more the centre of oscillation moved towards dorsiflexion, the greater was the amount of integrated EMG. Table 2 shows an analysis of variance for children LP and FL. The differences between parts of the cycle were highly statistically significant. Figure 3 illustrates these results for child LP.

(B) RELATION OF THE REFLEX EMG TO THE SUCCESSIVE CENTRES OF OSCILLATION Additional evidence of the facilitatory influence of length on the reflex EMG of triceps surae was provided by the second procedure described in the Method section. A two way analysis of variance took into account the means of the results of five children for three centres of oscillation $\left(120^{\circ}, 110^{\circ}, 100^{\circ}\right)$ and three frequencies $(0 \cdot 25,0 \cdot 5,1 \mathrm{~Hz})$. There was a significant $(p<0.05)$ difference between the three centres of oscillation $(F=3.94)$. Figure 4 shows that for each frequency the integrated EMG increased with the muscle length, which corresponded to decreasing tibia-calcaneal angles. Our procedure was not adapted to provide new evidence for the well known influence of frequency (that is velocity), as explained in Methods. Figure 4, which seems to indicate this influence of the frequency is not sufficiently convincing.

\section{(C) RAMP MOVEMENTS}

For the reasons given in Methods, quantitative data could be obtained in only five children. The integrated EMG increased with the muscle length when sequential steps of equal amplitude $\left(20^{\circ}\right)$ and equal velocity were performed. These results were compared by analysis of variance for four

Table 1 Quantity of integrated EMG for the 6 parts of the cycle. The results are expressed in percentage of data measured during part 3 of the cycle (maximum length and decreasing positive velocity). $n=$ No of cycles. Frequency $=0.25 \mathrm{~Hz}$.

\begin{tabular}{|c|c|c|c|c|c|c|c|}
\hline Case & $n$ & 1 & 2 & 3 & 4 & 5 & 6 \\
\hline $\begin{array}{l}\text { LP } \\
\text { FL }\end{array}$ & $\begin{array}{l}45 \\
27\end{array}$ & $\begin{array}{l}21 \cdot 1 \pm 2 \cdot 1 \\
31 \pm 1 \cdot 6\end{array}$ & $\begin{array}{ll}* 70 & \pm 4 \\
* 74 \cdot 8 & \pm 2 \cdot 6\end{array}$ & $\begin{array}{l}*_{1}^{*} 100 \\
*_{1} 00\end{array}$ & $\begin{array}{ll}* 5 & \pm 0 \cdot 7 \\
* 60 \cdot 1 & \pm 2 \cdot 7\end{array}$ & $\begin{array}{r}0 \cdot 7 \pm 0 \cdot 1 \\
* 17 \cdot 8 \pm 2 \cdot 2\end{array}$ & $\begin{array}{l}1 \cdot 4 \pm 0 \cdot 3 \\
* 5 \cdot 9 \pm 1\end{array}$ \\
\hline
\end{tabular}

*Comparison between the means of the successive parts of the cycle $(t$ test, $p<0.001)$.

For details of the division of the cycle into six parts, see text. 
Table 2 Two way analysis of variance for centres of oscillation and parts of the cycle in two children $(L P \& F L)$

\begin{tabular}{lllllllll}
\hline Child & $L P$ & & & & $F L$ \\
\cline { 2 - 4 } \cline { 6 - 8 } & $d f$ & $M S$ & $F$ & & $d f$ & $M S$ & $F$ \\
\hline $\begin{array}{c}\text { between centres of } \\
\text { oscillation } \\
\text { between parts of the } \\
\text { cycle }\end{array}$ & 4 & 499 & 165 & & 2 & 339 & 39 \\
\hline
\end{tabular}

Nine tests were undertaken in each situation.

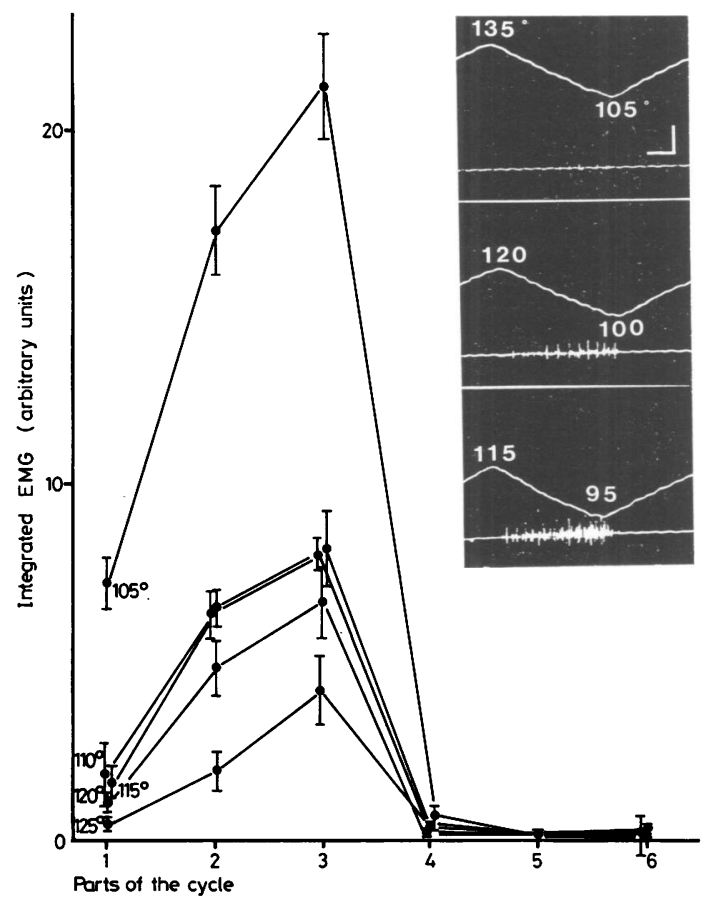

Fig 3 Relationship of integrated EMG (mean $\pm S E M$ ) in arbitrary units to the 6 parts of the cycle $(0.25 \mathrm{~Hz})$ at different centres of oscillations indicated on the left (amplitude of oscillation: $20^{\circ}$ ) (child LP). 1 arbitrary unit corresponded to $3.5 \mu \mathrm{V}$.s. Three data records of $L P$ for centres of oscillation of $120^{\circ}, 110^{\circ}, 105^{\circ}$ are shown in the insert. Calibrations: EMG, $100 \mu \mathrm{V}$ per unit; time, 500 ms per unit.

children (three steps, velocity about $100 \%$ s.). The difference was found significant $(\mathrm{p}<0.025, \mathrm{~F}=$ $5 \cdot 5)$. For child LP, rapid ramp movements triggered a clonus, but slow ramp movements $(40 \%)$ induced increasing EMG. Figure 5 shows the results for one child in whom four or five successive steps could be obtained at two different velocities.

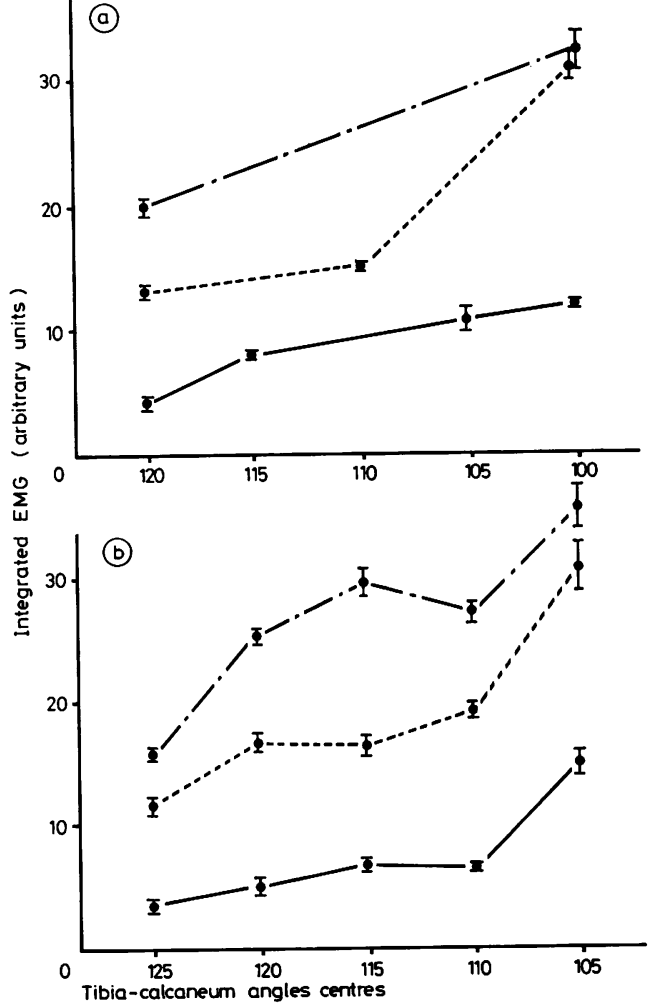

Fig 4 Relationship of integrated EMG (arbitrary units) and centres of oscillations (amplitude $20^{\circ}$ ).

Frequencies -. $-1 \mathrm{~Hz},--0.5 \mathrm{~Hz},-0.25 \mathrm{~Hz} .1$ arbitrary unit corresponds to $3.5 \mu V$.s. a: child $D A$, b: child LP. Means and SEM were calculated using each individual trial from every subject.

\section{Discussion}

Our aim was not to study all the characteristics of the abnormally increased stretch reflex of triceps surae, known to be present in some cerebral palsied children. It was only to investigate whether this stretch reflex was inhibited by increasing muscle length, as is the case for the increased stretch reflex of the quadriceps, or to a facilitory influence of length as occurs in hamstrings and muscles of the upper limb. ${ }^{8-11}$ In cerebral palsied children no inhibitory influence of length was observed, and when precise examination was possible, there was evidence of a facilitory influence of length on the stretch reflex of triceps surae. It would have been of interest to look for the influence of length on the increased stretch reflex of quadriceps in these cerebral palsied children. Unfortunately, in our patients, the threshold speed of the reflex was too 


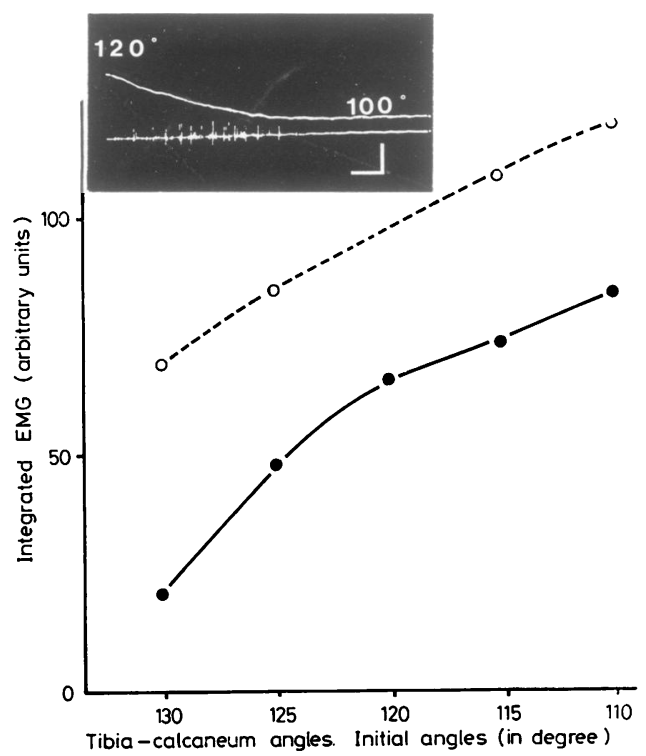

Fig 5 Child OA. Relationship of integrated EMG and $20^{\circ}$ amplitude ramp movements initiated at different angles (1 arbitrary unit corresponds to $3.5 \mu \mathrm{V} . \mathrm{s})$. Mean velocity $(100 \%$ s $)$. Rapid velocity $\bigcirc \ldots$ $\left(170^{\circ} / \mathrm{s}\right)$. A slow ramp movement from child LP is shown in the insert. Calibrations: EMG, $100 \mu \mathrm{V}$ per unit; time, $200 \mathrm{~ms}$ per unit. For a ramp movement between $140^{\circ}$ and $120^{\circ}$ there was no EMG activity.

high to allow such a study. However, we observed clinically a clear inhibitory influence of length on the quadriceps stretch reflex in some of these children.

Why does the spastic triceps behave in a manner similar to that of the hamstrings and muscles of the upper limb, but opposite to that of the quadriceps? Our study cannot answer the question, nor can we choose between the various interpretations of the inhibitory influence concerning the part played by: (a) the secondary endings and their group II afferent fibres;14-18 (b) the activity of Golgi tendon organs and their group IB afferent fibres; (c) the groups III and IV; and (d) possibly non-spindle group II. ${ }^{4}$ Our aim in this study was, to show that it is incorrect to include the clasp knife phenomenon in the definition of "spastic" muscles.

\section{References}

${ }^{1}$ Charcot JM. Leçons sur les maladies du système nerveux. Tome II (1873) 276-279. 1 vol. 144. Paris
Delahaye Edit.

${ }^{2}$ Sherrington C. On plastic tonus and proprioceptive reflexes. Quart J Exper Physiol 1909;2:109-56.

${ }^{3}$ Liddel EGT, Sherrington CS. Reflexes in response to stretch (myotatic reflexes). Proc Roy Soc London 1924;B96:212.

${ }^{4}$ Rymer WZ, Houk JC, Crago PE. Mechanisms of the clasp-knife reflex studied in an animal model. Exp Brain Res 1979;37:93-113.

${ }^{5}$ Herman R. The myotatic reflex. Clinicophysiological aspects of spasticity and contracture. Brain 1970; 93:273-312.

${ }^{6}$ Ashby P, Burke D. Stretch reflex in the upper limb of spastic man. J Neurol Neurosurg Psychiatry 1971; 34:765-71.

7 Tardieu G, Lacert P. Le tonus et ses troubles en clinique. Encyclopédie Médico-chirurgicale, Neurologie, chapitre 17007 A 20, 1977.

${ }^{8}$ Burke D, Gillies JD, Lance JW. The quadriceps stretch reflex in human spasticity. $J$ Neurol Neurosurg Psychiatry 1970;33:216-23.

${ }^{9}$ Burke D, Andrews CJ, Ashby P. Autogenic effect of static muscle stretch in spastic man. Arch Neurol $1971 ; 25: 367-72$.

${ }^{10}$ Burke D, Andrews CJ, Gillies JD. The reflex response to sinusoidal stretching in spastic man. Brain 1971; Part III 94:455-470.

11 Burke D, Gillies JD, Lance JW. Hamstrings stretch reflex in human spasticity. $J$ Neurol Neurosurg Psychiatry 1971;34:231-5.

12 Tardieu C, Colbeau-Justin P, Bret MD, Lespargot A, Huet de la Tour E, Tardieu G. An apparatus and a method for measuring the relationship of triceps surae torques to the tibio-tarsal angles in man. Eur J appl Physiol 1976;35:11-20.

13 Tardieu C, Bret MD, Colbeau-Justin P, Huet de la Tour E. Relationship of triceps surae torques to photographed tibia-calcaneum angles in man II. Eur J Appl Physiol 1977;37:153-61.

${ }^{14}$ Eccles RM, Lundberg A. Synaptic actions in motoneurones by afferents which may evoke the flexion reflex. Arch Ital Biol 1959;97:199-221.

${ }^{15}$ Laporte Y, Bessou P. Modifications d'excitabilité de motoneurones homonymes provoquées par l'activation physiologique de fibres afférentes d'origine musculaire du groupe II. J Physiol (Paris) $1959 ; 51: 897-08$.

16 Matthews PBC. Mammalian muscle receptors and their central actions. 1972; 630. London. Arnold Edit.

17 Burke D, Knowles L, Andrew C, Ashby P. Spasticity, decerebrate rigidity and the clasp-knife phenomenon. An experimental study in the cat. Brain 1972;95: 31-48.

18 Burke D, Ashby P. Are spinal "presynaptic" inhibitory mechanisms suppressed in spasticity? $J$ Neurol Sci 1972;15:321-6. 